\title{
Exploring consumer behavior in fitness centers with an emphasis \\ on mediating effects of psychological well-being
}

\author{
Yunduk Jeong, Jae-Gu Yub, Jaeyoung Shim ${ }^{\mathrm{c}}$, \& Eun Choi ${ }^{\mathrm{d}}$ * \\ ${ }^{a}$ Assistant Professor, College of General Education, Kookmin University \\ ${ }^{b}$ Assistant Professor, Department of Sport Industry, Chungang University \\ ${ }^{c}$ Assistant Professor, Sehan University \\ ${ }^{d}$ Lecturer, Sookmyung Women's University
}

\begin{abstract}
The aim of this study was to examine the structural relationships among sport participation motivation, psychological well-being, life satisfaction and revisit intention with an emphasis on exploring mediating effects of psychological well-being on the relationships among the research variables. Participants, who were members of a fitness center, completed surveys to assess these relationships. Results showed that sport participation motivation leads to psychological well-being and revisit intention, and psychological well-being is a critical factor in influencing life satisfaction and revisit intention. Moreover, the path from sport participation motivation and life satisfaction was fully mediated by psychological well-being, and the path from sport participation motivation and revisit intention was partially mediated by psychological well-being, which underlines the importance of mediation role of psychological well-being. These results imply that fitness managers should manage sport participation motivation and psychological well-being of customers.
\end{abstract}

Key words: sport participation motivation, psychological well-being, life satisfaction, revisit intention, pilates

\section{Introduction}

In an increasingly saturated marketplace, competitive fitness center organizations should redesign their marketing strategies or commit considerable resources to secure consumer loyalty and build long-term relationships with their customers (Baek, 2005). Pilates has received much attention from scholars for many

Submitted : 2 June 2020

Revised : 6 July 2020

Accepted : 5 August 2020

Correspondence: eunch1009@daum.net years because it has been generally recognized to provide an effective means of stably forming fitness center customer loyalty because it is believed that Pilates offers a variety of physical and mental benefits (Kim, 2019). Pilates is known to help back rehabilitation and provide complete coordination of mind and spirit and develop trunk muscles and restore muscle balance (Memmedova, 2015; Sekendiz, Altun, Korkusuz \& Akın, 2007; Petracovschi, 2014). Due to these positive effects, in recent years, Pilates have proliferated among the fitness centers in the past decade (Petracovschi, 
2014). Many researchers expect more and more people to participate in Pilates all over the world. Moreover, in recent years, majority of studies have listed the many psychological benefits of participating Pilates (Kim and Oh, 2017; Lee and Jung, 2019; Roh, 2016). Choi and Kwak (2020) examined the psychological aspect of Pilates participants, and demonstrated that sub-factors of psychological happiness such as self-realization, delight, and competence have a considerable impact on their willingness to continue workout. Therefore, based on these findings, fitness center marketers may need to identify the psychological aspects of the Pilates participants and establish marketing strategies to the future success of fitness centers.

From the psychological point of view, sport participation motivation is currently receiving new emphasis among scholars, since it is a significant factor affecting behavioral intention (De Pero et al, 2009). In other words, sport participation motivation includes the processes of joining, continuation, and withdrawal in relation to sport activities (Weiss \& Petlichkoff, 1989). Harter' (1978) theory of motivated behavior provides some useful evidence on motivation in sport. According to her theory, perceived competence, adequacy and social support influence perception of self-worth which affects enjoyment and physical activity behavior (Weiss, 2000). Seen in this perspective, sport participation motivation should be emphasized for understanding the psychological aspects of consumers.

There has been a general recognition of the effect motivation on psychological well-being that is a frequent topic in America and Asia. Namely, psychological well-being has long constituted an important domain of research in social psychology. There are three main approaches regarding psychological well-being (Wright \& Cropanzano, 2000): one argues that it is a phenomenological event (Diener, 1994), another maintains "it includes some emotional conditions" and The other insists "it refers to one's life as a whole" (Wright et al, 2000, p.84). It is a task of great significance to deal with psychological well-being in this study because fitness center customers ultimately pursue happiness through physical activity (Scully, Kremer, Meade, Graham \& Dudgeon, 1998).

If feeling positive subjective experience through Pilates, customers may operate as an individual strength (Suldo \& Huebner, 2004). In other words, they accumulate experience life in satisfying ways, which can lead to life satisfaction. Like the importance of psychological well-being, what customers finally want to gain from physical activity at fitness centers may be to increase their life satisfaction. Likewise, previous research on life satisfaction has suggested that life satisfaction is an important factor in understanding the adult life and determinant of many life outcomes (Suldo et al, 2004). Therefore, a degree of customers' life satisfaction should be considered important to increase the attraction of them.

Over the years, revisit intention has received much attention in the business, tourism, and sport management because it is an important driving force of economic development as the marketing cost to retain customers can be reduced efficiently (Um, Chon \& Ro, 2006). Therefore, exploring the factors directly affecting customers' revisit intention of fitness centers can provide marketers with strategies to improve the economic level of the fitness centers. Numerous scholars have reported that it is likely that motivation and satisfaction influence revisit intention (Raza, Siddiquei, Awan \& Bukhari, 2012; Un et al, 2006).

The contribution of this research is twofold. First, this research responds to recent calls for researchers to develop and test "global" or "integrative" models in social science research (Prayag, Hosany, Muskat \& Del Chiappa, 2017). More specifically, this study expands current theorizations by examining the merits of including both life satisfaction and revisit intention. Traditionally, in the context of sport industry, existing studies can be classified into two main categories; the first group focuses on exploring the relationship between motivation and life satisfaction (Kang and Park, 2019). The second research stream concentrates 
on investigating the relationship between motivation and loyalty (akin revisit intention) (Yu, Hwang, and Park, 2010). There is currently no study that examines the positive relationship among sport participation motivation, psychological well-being, life satisfaction and revisit intention. Next, there has been minimal research concerning the mediate effects of psychological well-being between sport participation motivation and life satisfaction, and sport participation motivation and revisit intention. Exploring the mediating effects of psychological well-being could be a new perspective in understanding future consumer behaviours. Accordingly, to address these gaps in the available literature, the aim of this paper is to explore the structural relationship among four variables, with an emphasis on the mediate effect of psychological well-being, which can provide fitness center marketers with some useful information with respect to marketing strategies.

\section{Literature Review and Research Hypotheses}

Motivation has received maximal attention from Western scholarship and it can be viewed as the forces that initiate, direct and sustain human behavior (Iso-Ahola, 1999). Previous studies suggest that the motivation construct has been conceptualized as being intrinsic, extrinsic and amotivation (Alexandris, Tsorbatzoudis \& Grouios, 2002). According to Ryan and Deci (2000, pp. 56), "intrinsic motivation is defined as the doing of an activity for its inherent satisfaction rather than for some separable consequence." When intrinsically motivated people are moved to behave for the joy or challenge entailed rather than due to external prods, pressures, or rewards. The phenomenon of intrinsic motivation was first supported within experimental studies of animal behaviour, where it was found that a lot of organisms participate in exploratory, playful, and curiosity-driven behaviours even in the absence of reinforcement or reward (White, 1959). In humans, intrinsic motivation is not the only form of motivation, or event of spontaneous activity, but it is a widespread and significant one.

Though intrinsic motivation is highly an important type of motivation, a lot of the activities people do are not, strictly speaking, intrinsically motivated. In schools, for example, it is likely that intrinsic motivation becomes waker with each advancing grade. Extrinsic motivation refers to "doing an activity simply for the enjoyment of the activity itself, rather than its instrumental value.” (Ryan \& Deci , 2000, pp. 60). For instance, a student who does his homework only because he fears parental sanctions for not doing it is extrinsically motivated because he is doing the work to gain the separable outcome of avoiding sanctions (Ryan \& Deci, 2000). Similarly, an employee who does the work because he or she personally believes it is valuable for his or her chosen career is also extrinsically motivated because he or she too is doing it for its instrumental value rather than because he or she finds it excitement. Amotivation is related to the condition of lacking an intention to participate sport, which derive from not valuing an activity (Ryan, 1995). When amotivated, a person's behaviour lacks intentionality and a sense of personal causation. Amotivation results from not valuing an activity, not feeling competent to do it, or not believing it will yield a desired outcome (Deci, 1975; Ryan, 1995; Seligman, 1975).

Previous studies show motivation can lead to psychological well-being. Interesting observation on the relationship between motivation and psychological well-being can be found in Deci and Ryan (2008)'s study. They found motivation is coupled with psychological well-being. Kim, Jeong, and Ha (2018) tested the influence of sport motivation and psychological well-being on satisfaction and behavioural intention of golf participants and indicated that sport motivation is a direct antecedent of psychological well-being. Choi and Moon (2010) investigated the relationships among Aquatic exercise participants' motivation, psychological well-being and 
behaviour after participating and showed motivation is inclined to build psychological well-being. Ho and Lee (2017) analysed a study on relation between leisure motivation and leisure flow, leisure satisfaction and psychological well-being, revealing that leisure motivation is an important factor in affecting psychological well-being. Similarly, in recent years, Oh (2019) explored the structural relationships between motivation of self-determination of participants in Pilates' activities, psychological well-being, satisfaction and behavior, indicating that motivation has an impact on psychological well-being. In general, past findings confirm that motivation is a direct antecedent of life satisfaction. Sirgy et al. (2013) examined the relationship among motivation, life satisfaction and satisfaction with material life, demonstrating motivation contributes to life satisfaction. Kang and Park (2019) explored the structural relationship among the participation motive, physical health, emotional health, and life satisfaction of the sports welfare service participants and found that motive plays a key role in predicting life satisfaction. Similarly, in the context of Pilates, Kim and Kim (2018) empirically analysed the relationships between participation motives, flow, satisfaction, and intention of exercise adherence and demonstrated that motives lead to satisfaction.

Moreover, the goal valence principle is introduced to establish the theoretical framework for our proposed model. The goal valence principle notes that satisfaction is enhanced by intrinsic motivation such as goal attainment (Sirgy, 2010). To fully understand the goal valence principle, we have to recognize that inherent in this principle is an assumption of a bottom-up spillover effect (Campbell, Converse and Rodgers, 1976). Specifically, consumers experience positive or negative feelings concerning their experiences to a product or service. These feelings may contribute direclty to life satisfaction through psychological well-being. Similarly, life satisfaction is influenced by satisfaction with life domains (e.g., satisfaction with family, social life and so on) (Sirgy, 2010), which means extrinsic motivation. In addition, exploring the impact of motivation on revisit intention, Pratminingsih, Rudatin \& Rimenta (2014) reported motivation has a key role in predicting revisit intention. Whang and Kim (2018) investigated the effect of the motivation of the Himalayan trekking on leisure satisfaction and revisit intention and demonstrated that motivation is a predictor of revisit intention. Therefore, the following hypotheses will be tested:

H1: Sport participation motivation will positively influence psychological well-being.

H2: Sport participation motivation will positively influence life satisfaction.

H3: Sport participation motivation will positively influence revisit intention.

Psychological well-being studies have proliferated as major focus of various research over the past few years. Psychological well-being can be defined as a feeling of happiness and satisfaction (Mannell \& Kleiber, 1997) and consist of happiness, quality of life, and life satisfaction (Gilbert \& Abdullah, 2004). In other words, for this approach, well-being relates feeling good. This approach to well-being is limited as it takes no account of the importance of life experiences having a purpose (Ryff \& Singer, 2008). The other, complementary, approach to well-being takes account of the importance of the "purpose" in well-being. This approach is usually referred to as the "eudaimonic" approaches to well-being, it helps to distinguish between experiences and feeling of well-being (Ryff \& Singer, 2008). For example, a lot of people tend to accept that an unrelenting series of what are intially pleasurable experiences will gradually become less enjoyable and fail to product the same positive emotional experience.

Locker, Clarke \& Payne (2000) insisted psychological well-being can be regarded as one of the main precursors of life satisfaction. Yoon and Kim (2019) tested the influence of psychological well-being on attitude and satisfaction in the participants in the 
college physical education, emphasizing that psychological well-being is related to the formation of satisfaction. Lin (2014) examined a structural model with respect to the effect cuisine experience, psychological well-being on revisit intention and found psychological well-being are important determinants of revisit intention. Therefore, the following hypotheses will be tested:

H4: Psychological well-being will positively influence life satisfaction.

H5: Psychological well-being will positively influence revisit intention.

Curiously, despite the psychological well-being studies as an academic discipline, few have attempted to address the mediate effect of psychological well-being between sport participation motivation and life satisfaction, and sport participation motivation and revisit intention. However, we infer them through each positive relationship among variables. As we have seen, sport participation motivation can be linked with life satisfaction (Sirgy et al., 2013), and psychological well-being (Deci et al., 2008) and psychological well-being can be coupled with life satisfaction (Locker et al., 2000). Similarly, based on previous studies, sport participation motivation can be associated with revisit intention (Pratminingsih et al., 2014), and psychological well-being can be connected with revisit intention (Lin, 2014). Therefore, the following hypotheses will be tested:

H6: Psychological well-being will mediate between sport participation motivation and life satisfaction.

H7: Psychological well-being will mediate between sport participation motivation and revisit intention.

\section{Methods}

\section{Participants}

We collected our study data from Pilates participants at large fitness centers in Seoul and Busan, South Korea. To collect a sample, a team of three trained research assistant administered face-to-face questionnaire-based surveys at the information desk of fitness centers from 15 to 30 September, 2019 using a convenience sampling method. This location represented effective means to obtain a sample of Pilates participants. We approached 293 respondents and they were informed of the research purpose and invited to participate on a voluntary basis. Participants were not actively solicited to participate.

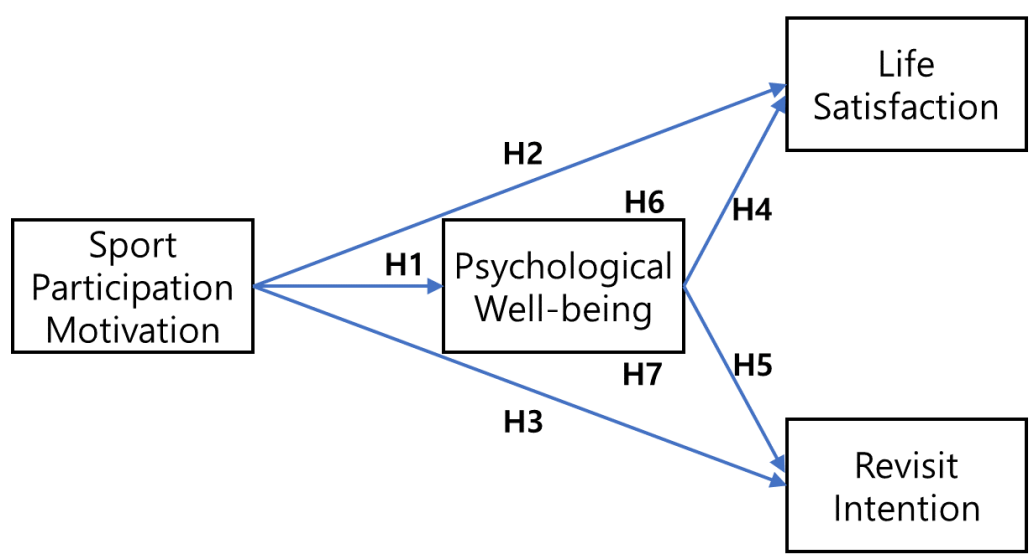

Figure 1. The Research Model 
Consequently, 273 questionnaires were collected, but 20 were subsequently eliminated because some important questions were not answered. The remaining 253 satisfactorily completed questionnaires were analysed. Most of the participants were women $(71.1 \%, n=180)$, aged between 20 and 29 (58.5\%, n=148), single (67.6\%, $171)$, and in college now or graduate $(41.5 \%, \mathrm{n}=105)$ (see Table 1).

Table 1. Demographic characteristic of participants

\begin{tabular}{cccc}
\hline \hline Variables & Categories & $\mathrm{N}$ & $\%$ \\
\hline \multirow{2}{*}{ Gender } & Male & 73 & 28.9 \\
& Female & 180 & 71.1 \\
\hline \multirow{3}{*}{ Age } & $20-29$ & 148 & 58.5 \\
& $30-39$ & 65 & 25.7 \\
\hline \multirow{4}{*}{ Marital } & $>40$ & 40 & 15.8 \\
\hline \multirow{4}{*}{ status } & Single & 171 & 67.6 \\
& Married & 69 & 27.3 \\
& Divorced & 9 & 3.5 \\
\multirow{3}{*}{ Education } & Others & 4 & 1.6 \\
& High school graduate & 59 & 23.3 \\
& college now or graduate & 105 & 41.5 \\
& Advanced degree & 61 & 24.1 \\
\hline \hline
\end{tabular}

\section{Measures}

Respondents were asked to answer each item using a 7-point Likert-type scale, anchored on strongly disagree (1) and strongly agree (7). The survey contained 20 items, of which sport participation motivation items were sourced from Pelletier et al. (1995). As we have mentioned before, the literature has identified three categories of sport participation motivation: Intrinsic motivation, Extrinsic motivation, and amotivation. Although various measures have been adopted, Pelletier et al (1995)'s measure have been favoured in many studies, typically in the field of sport social science, because the scale displays stronger validity and reliability (Jung and Yoo, 2016; Lee, Lee and Moon, 2020; Park, Lee and Moon, 2020).
Psychological well-being was operationalized by 6 items, which were adopted form Ryff (1989). life satisfaction was operationalized by 5 items, which were drawn from Diener, Emmons, Larsen \& Griffin (1985). Revisit intention was operationalized by 4 items, which were derived from Maxham III (2001) and Maxham and Netemeyer (2002). (see Table 2).

Once a preliminary questionnaire to measure each construct was established, a panel of three experts (sport management and psychology professors) reviewed the scales for content validity. Items were examined based on whether the format and constructs were (a) appropriate, (b) adequate/representative, and (c) accurate/clear. Based on the feedback provided by the panel of experts, the preliminary questionnaire was modified, revised, and improved mainly in the areas of adequacy, test format, factor relevance, and wording clarity.

\section{Data Analysis}

Date collected from the questionnaire were computed using the SPSS 22.0 and AMOS 22.0 software. SPSS was used to conduct frequency and reliability. AMOS was used to investigate confirmatory factor analysis, the positive relationships, and the mediating effect of psychological well-being.

\section{Results}

\section{Confirmatory factor analysis}

In terms of data distribution, skewness and kurtosis for the scale items were within the recommended absolute values, indicating no violation of the normality assumption (Kline, 2005). Based on the theoretical background, confirmatory factor analysis was performed to statistically confirm the relationship between manifest variables and latent variables. The four-factors (sport participation motivation, psychological well-being, life satisfaction and revisit intention) CFA model for a total had 164 degrees of freedom. The model fit results for 
the four-factors CFA model for OCB revealed acceptable model fit to the data $\left(x^{2}=288.359(d f=68)\right.$, $p<.000), \mathrm{x}^{2} / d f=1.758, \mathrm{NFI}=.905$, TLI=.903, CFI=.900, and RMSEA=.051). All the model fit indices were satisfactory within recommended thresholds. To evaluate the convergent validity, factor loadings were confirmed and a Construct Reliability (CR) and Average Variance Extracted (AVE) were analyzed. All factor loadings were greater than 0.55 and significant $(p<$ 0.001 ), with $t$ values exceeding the critical value of 3.29 (Kline, 2005). The values of CR all exceeded the recommended value of .07, ranging from .834 to .964.

Table 2. The questionnaire items

\begin{tabular}{|c|c|c|}
\hline \multicolumn{2}{|c|}{ Constructs } & Items \\
\hline \multirow{20}{*}{$\begin{array}{c}\text { Sport } \\
\text { Participation } \\
\text { Motivation }\end{array}$} & \multirow{12}{*}{$\begin{array}{l}\text { Intrinsic } \\
\text { Motivation }\end{array}$} & For the pleasure I feel in living exciting experiences \\
\hline & & For the pleasure it gives me to know more about the sport that I practice \\
\hline & & For the pleasure of discovering new training techniques \\
\hline & & For the pleasure I feel while improving some of my weak points \\
\hline & & For the excitement I feel when I am really involved in the activity \\
\hline & & Because I must do sports to feel good about myself \\
\hline & & For the satisfaction I experience while I am perfecting my abilities \\
\hline & & Because I must do sports regularly \\
\hline & & Because I like the feeling of being totally immersed in the activity \\
\hline & & For the intense emotions that I feel while I am doing a sport that I like \\
\hline & & $\begin{array}{l}\text { Because it is a good way to learn lots of things which could be useful to me in other areas } \\
\text { of my life }\end{array}$ \\
\hline & & $\begin{array}{l}\text { I used to have good reasons for doing sports, but now I am asking myself if I should } \\
\text { continue doing it }\end{array}$ \\
\hline & \multirow{5}{*}{$\begin{array}{l}\text { Extrinsic } \\
\text { Motivation }\end{array}$} & Because it allows me to be well regarded by people that I know \\
\hline & & Because, in my opinion, it is one of the best ways to meet people \\
\hline & & Because people around me think it is important to be in shape \\
\hline & & To show others how good I am at my sport \\
\hline & & Because it is one of the best ways to maintain good relationships with my friends \\
\hline & \multirow{3}{*}{ Amotivation } & I often ask myself; I cannot seem to achieve the goals that I set for myself \\
\hline & & It is not clear to me anymore; I do not really think my place is in sport \\
\hline & & I do not know anymore; I have the impression that I am incapable of succeeding in this sport \\
\hline \multirow{6}{*}{\multicolumn{2}{|c|}{ Psychological Well-being }} & I have no fear of speaking my opinion when I disagree with others \\
\hline & & I am good at handling things so I can fit myself into everything I have to accomplish \\
\hline & & \begin{tabular}{|l} 
For me, life was constant process of learning and self-growth \\
\end{tabular} \\
\hline & & I know I can trust my friends and they can trust me too \\
\hline & & I am active in carrying out the plans I have made for myself \\
\hline & & I like most of my personality \\
\hline \multirow{5}{*}{\multicolumn{2}{|c|}{ Life Satisfaction }} & Most of my life is ideal \\
\hline & & \begin{tabular}{|l|} 
The conditions of my life are excellent \\
\end{tabular} \\
\hline & & I am satisfied with my life \\
\hline & & So far, I have got the important thing I want in life \\
\hline & & I do not want to change most of me if I am born again \\
\hline \multirow{4}{*}{\multicolumn{2}{|c|}{ Revisit Intention }} & I will go the Fitness center \\
\hline & & I will go the Fitness center in my spare time \\
\hline & & I expect to go the Fitness center \\
\hline & & I want to go the Fitness center \\
\hline
\end{tabular}


and the values of AVE all exceeded the recommended value of .05 , ranging from .713 to .845 .

For discriminant validity, we verified that the AVE of the latent variable is greater than the square of the correlation between latent variables (Fornell \& Larcker, 1981). Since it is difficult to verify all variables, the pair with the highest correlation between variables is selected and verified. The highest correlation is 0.650 (psychological well-being - revisit intention), (0.845) ${ }^{2}=0.422$, psychological well-being AVE is 0.845 , and revisit intention AVE is 0.779. Since the AVE values are all greater than the square of the correlation coefficient, discriminant validity is found.

\section{Reliability}

The results revealed that Cronbach's alpha coefficients of sport participation motivation scales ranged from .701 to .911, psychological well-being scales were .852 , life satisfaction scales were .885 , and revisit intention scales were .954, respectively. All in all, the scales presented acceptable reliability (Nunnally \& Bernstein, 1994).

\section{Results of structural model}

The hypothesized positive relationship among the proposed constructs were tested and found to have an adequate level of fit $\left(\mathrm{x}^{2} / d f=1.823, \mathrm{NFI}=.911, \mathrm{CFI}=.907\right.$,
CFI=.901 and RMSEA=.059). To analyse the relationship among constructs, the influences between variables were verified and the following conclusions were drawn.

First, sport participation motivation had a significant effect on psychological well-being (.367, $\mathrm{p}<.000$ ). Therefore, hypothesis 1 was supported. Second, sport participation motivation had not a significant effect on life satisfaction $(-.043, \mathrm{p}<.410)$. Therefore, hypothesis 2 was not supported. Third, sport participation motivation had a significant effect on revisit intention (.189, $\mathrm{p}<.000)$. Therefore, hypothesis 3 was supported. Fourth, psychological well-being had a significant effect on life satisfaction (.741, $\mathrm{p}<.000)$. Therefore, hypothesis 4 was supported. Fifth, psychological well-being had a significant effect on revisit intention (.591, $\mathrm{p}<.000)$. Therefore, hypothesis 5 was supported.

Sixth, the mediating effects of psychological well-being in the relationship between sport participation motivation and life satisfaction was statistically significant. In other words, it showed full mediating effect. Therefore, hypothesis 6 was supported. Seventh, the mediating effects of psychological well-being in the relationship between sport participation motivation and revisit intention was statistically significant. In other words, it had a partial mediating effect. Therefore, Hypothesis 7 was supported.

Table 3. Results of structural equation modeling analysis and hypothesis test

\begin{tabular}{cccccc}
\hline \hline Hypothesis & Path & $\begin{array}{c}\text { Standardized } \\
\text { Coefficient }\end{array}$ & C.R. & $p$ & $\begin{array}{c}\text { Test } \\
\text { Results }\end{array}$ \\
\hline 1 & $\begin{array}{c}\text { Sport participation motivation } \\
\text { Psychological well-being } \\
\text { Sport participation motivation } \rightarrow\end{array}$ & .367 & 5.531 & .001 & Accepted \\
$\quad \begin{array}{c}\text { life satisfaction } \\
3\end{array}$ & $\begin{array}{c}\text { Sport participation motivation } \\
\text { Revisit intention } \\
\text { Psychological well-being } \rightarrow \\
\text { life satisfaction }\end{array}$ &. .043 & -.824 & .410 & Rejected \\
4 & $\begin{array}{r}\text { Psychological well-being } \rightarrow \\
\text { Revisit intention }\end{array}$ & .741 & 3.598 & .001 & Accepted \\
5 & .591 & 8.727 & .001 & Accepted \\
\hline \hline
\end{tabular}


Table 4. Mediating effects of psychology well-being

\begin{tabular}{ccccccc}
\hline \hline & Path & Estimate & SE & $\begin{array}{c}\text { 95\% CI } \\
\text { (Bias-corrected) }\end{array}$ & $p$ \\
\hline Sport participation & Indirect effect & .248 & .059 & $.155 \sim .365$ & .005 \\
motivation $\rightarrow$ & Direct effect & .014 & .062 & $-.100 \sim .108$ & .810 \\
life satisfaction & Total effect & .262 & .082 & $.143 \sim .423$ & .005 \\
\hline \multirow{2}{*}{ Sport participation } & Indirect effect & .186 & .043 & $.125 \sim .269$ & .004 \\
motivation $\rightarrow$ & Direct effect & .251 & .059 & $.165 \sim .358$ & .007 \\
Revisit intention & Total effect & .437 & .075 & $.325 \sim .560$ & .009 \\
\hline \hline
\end{tabular}

\section{Discussion}

The purpose of this study was to investigate a model regarding the relationships among sport participation motivation, psychological well-being, life satisfaction and revisit intention. Extending current theorizations and congruent with research in sport, this study reveals the predictive power of motivation in sport. In particular, the proposed integrative framework allows the identification of relationships between (1) sport participation motivation and psychological well-being; (2) sport participation motivation and revisit intention; (3) psychological well-being and life satisfaction; and (4) psychological well-being and revisit intention. The results underline that sport participation motivation or psychological well-being are important predictors of life satisfaction or revisit intention. From a theoretical point of view, the current study offers several implications to research in sport.

First, this study provides strong support for the notion that motivation directly affects psychological well-being, which in in line with previous studies. For example, Peng, Kim and Lee (2018) examined a study on the relationship between participation motivation and psychological well-being of sports for all programme participants in China and showed that motivation importantly boosts psychological well-being. Kim and Kim (2017) explored the relationship among motivation, exercise passion, and psychological well-being of crossfit participants, indicating that motivation leads to psychological well-being. Jeong (2018) investigated a hierarchical regression analysis model regarding motivation of college soccer players and found that motivation indirectly affects psychological well-being through exercise commitment and physical self-efficacy. Thus, this study strengthens the view that motivation should be considered a priority by fitness center marketers.

Second, the present study embraces the argument of previous researchers by seeking to understand the role of motivation in the context of sport marketing. More specifically, existing studies noted that motivation is a key consideration of marketing strategies focused on revisit intention, and they called for further research in other settings. For instance, Choi and Moon (2010) analysed the relationships among motivation, psychological well-being and behaviour after participating, showing motivation is associated with intention to revisit. Choi (2012) explored the relationship between motivation, service physical environment, satisfaction, and revisit intention among screen golf customers, and reported that motivation importantly boosts revisit intention. In the context of active sport tourism literature, Choi (2007) tested the relationship among golf tourists' participation motivation, the attribute of the destination, satisfaction, complaining behaviour and revisit intention, underlining motivation indirectly influences revisit intention. Thus, our findings suggest that it would be worthwhile for fitness center marketers to make greater investments to form customers' motivation. In addition, contrary to expectations, a result fail to support the effect of sport 
participation motivation on life satisfaction. A plausible explanation relates to the fact that customers have higher propensity to revisit the fitness center, irrespective of the level of life satisfaction. We can naturally assume that life has nothing to do with intention to revisit a fitness center.

Third, the present study provides empirical evidence of relations between the formation of psychological well-being and life satisfaction, and psychological well-being and revisit intention. Surprisingly, in contrast to the voluminous scholarship on psychological well-being, there have been few studies on exploring the relationship between the important factors. Nevertheless, some studies are in line with our findings. For example, Lin (2014) and Locker et al. (2000) reported that psychological well-being is positively woven into life satisfaction and revisit intention. Thus, this study supports the conclusion that psychological well-being is coupled with life satisfaction and revisit intention, which points to several promising applications for future research.

Fourth, the current study contributes to sport marketing studies by demonstrating the effects of psychological well-being that mediate between sport participation motivation and life satisfaction, and sport participation motivation and revisit intention. More specifically, psychological well-being fully mediates the relationship between sport participation motivation and life satisfaction, and partially mediates the relationship between sport participation motivation and revisit intention. The findings revealed that sport participation motivation is only determined by life satisfaction through psychological well-being, and psychological well-being plays a mediation role between sport participation motivation and revisit intention. In this regard, the findings contributed to the sport marketing literature in confirming the important mediating effect the link between sport participation motivation and life satisfaction, sport participation motivation and revisit intention.

Therefore, it is essential for fitness center marketers to gain a better understanding of what drives customer behavior. Grasping and managing sport participation motivation and psychological well-being in target customers' minds is a significant key to sustainable fitness success. Hence, fitness center marketers should actively promote the benefit of Pilates. As we have seen, Pilates help a physical and psychological development. To maximize these benefits, fitness center managers should develop new programs and classes for Pilate's customers, which can contribute to friendship among them. In addition, with respect with the importance of mediating effects of psychological well-being on the relationships among the research variables, marketers should view the concept of psychological well-being important in terms of survival of the fittest and future success of a fitness center. Thus, we encourage marketers to develop advertising and communication campaigns about positive emotions such as joy, pleasure, excitement, comfortableness, and sense of achievement formed by participating Pilates. Furthermore, to evoke consumers' positive emotions further, personal fitness trainers may provide them with fitness programs which include five elements: aerobic fitness, strength training, core exercises, balance training, and flexibility and stretching. Aerobic activity refers to cardio or endurance activity, core exercises helps protect consumers' back and connect upper and lower body movements, balance exercises can help consumers maintain their balance at any age, and it's a good idea to include flexibility and stretching activities in a fitness program.

\section{Conclusion}

The objectives of the current study were to determine the nature of relationships between sport participation motivation, psychological well-being, life satisfaction, and revisit intention with an emphasis on the mediating effects of psychological well-being in the sport marketing environment using an integrated model. The proposed model allowed the identification of relations 
between (1) sport participation motivation and psychological well-being, (2) sport participation motivation and revisit intention, (3) psychological well-being and life satisfaction, and (4) psychological well-being and revisit intention, and showed that psychological well-being had a full mediating effect on the relationship between sport participation motivation and life satisfaction, and psychological well-being had a partial mediating effect on the relationship between sport participation motivation and revisit intention. The present study offers several contributions to research in sport marketing. For instance, first, this study offers strong support for the notion that motivation plays a pivot role in improving psychological well-being. Second, the current study embraces the argument of previous researchers by seeking to understand the role of motivation in the context of sport marketing. Third, the present study offers empirical evidence of relationships between the formation of psychological well-being and life satisfaction, and psychological well-being and revisit intention. Fourth, this study contributes to the development of sport marketing studies by demonstrating the mediating effects of psychological well-being.

This study is not without limitations. First, sport participation motivation and psychological well-being were examined as antecedents to revisit intention. However, additional factors may affect and interact with revisit intention. Future researchers are advised to conduct additional factors. Second, psychological well-being was analyzed as a mediating variable between sport participation motivation and life satisfaction and revisit intention, but another mediating variable may act in the proposed model. Future studies should examine an additional mediating variable for extending the model. Third, future studies should analyze the moderating variables such as situational factors, which can offer a new interpretation of research of fitness center marketing. Fourth, these findings are limited to some fitness centers in South Korea, and were collected at specific places and time of year.
Consequently, our findings cannot be generalized to sport customers. Future research could study sport customers at different locations to increase the generalizability of the results.

\section{References}

Alexandris, K., Tsorbatzoudis, C., \& Grouios, G. (2002). Perceived constraints on recreational sport participation: Investigating their relationship with intrinsic motivation, extrinsic motivation and amotivation. Journal of Leisure Research, 34(3), 233-252.

Baek, H. (2005). The influence of health club marketing mix factors on customer satisfaction and purchase behavior. Master Thesis, Dankook University, Seoul, Korea, Unpublished Work.

Campbell, A., Converse, P. E., \& Rodgers, W. L. (1976). The quality of American life: Perceptions, evaluations, and satisfactions. New York, NY: Russell Sage Foundation.

Choi, H. H., \& Kwak, J. H. (2020). The effects on physical self-efficiency of Pilates participants on psychological happiness and willigness to continue workout. Korean Society of Martial Arts, 14(1), 143-161.

Choi, J. D., \& Moon, T. Y. (2010). The relationships among Aquatic exercise participants motivation, psychological well-being and behavior after participating. Journal of Sport and Leisure Studies, 39, 775-786.

Choi, J. Y. (2012). (A) study on the relationship according to motivation for participation, service physical environment, satisfaction on participation and revisit decision-making between outdoor and creen golf practice range customers. Ph.D. Thesis, Hanyang University, Ansan, South Korea, 2012, Unpublished Work.

De Pero, R., Amici, S., Benvenuti, C., Minganti, C., Capranica, L., \& Pesce, C. (2009). Motivation for sport participation in older Italian athletes: the role 
of age, gender and competition level. Sport Sciences for Health, 5(2), 61-69.

Deci, E. L. (1975). Intrinsic motivation. New York, NY: Plenum.

Deci, E. L., \& Ryan, R. M. (2008). Facilitating optimal motivation and psychological well-being across life's domains. Canadian Psychology/Psychologie canadienne, 49(1), 14.

Diener, E. (1994). Assessing subjective well-being: Progress and opportunities. Social Indicators Research, 31(2), 103-157.

Diener, E. D., Emmons, R. A., Larsen, R. J., \& Griffin, S. (1985). The satisfaction with life scale. Journal of Personality Assessment, 49(1), 71-75.

Fornell, C., \& Larcker, D. F. (1981). Structural equation models with unobservable variables and measurement error: Algebra and statistics. Journal of Marketing Research, 18, 382-388.

Gilbert, D., \& Abdullah, J. (2004). Holidaytaking and the sense of well-being. Annals of Tourism Research, 31(1), 103-121.

Harter, S. (1987). The determinants and mediational role of global self-worth in children. Contemporary topics in developmental psychology. New York, NY: Wiley.

Ho, H. H., \& Lee, M. C. (2017). A study on relation between fitness center customer leisure motivation and leisure flow, leisure satisfaction, and psychological well-being. Korean Journal of Physical Education, 56(1), 487-501.

Iso-Ahola, S. E. (1999). Motivational foundations of leisure. Leisure studies: Prospects for the twenty-first century, State College, PA: University Press.

Jeong, Y. D. (2018). Hierarchical regression analysis model regarding intrinsic motivation of college soccer players. Korean Journal of Sport Management. 23(6), 91-106.

Jung, J. H., \& Yoo, J. I. (2016). The effect of sports star image on sport participation motivation and the satisfaction of physical education. Journal of Sport and Leisure Studies, 63, 131-143.

Kang, S. W., \& Park, J. J. (2019). The structural relationship among the participation motive, physical health, emotional health, and life satisfaction of the sports welfare service participants: Focusing on "National Physical Fitness 100”. Korea Convergence Society, 10(11), 401-410.

Kim, D. H. (2019). A literature review of the effects of Pilates on menopasue women. Korea Soceity for Wellness, 14(2), 405-417.

Kim, S. E., \& Kim, H. R. (2018). Association among sport flow, leisure satisfaction, and intention of exercise adherence according to participation motives of Pilates participants. Journal of Sport and Leisure Studies, 73, 317-330.

Kim, S. I., \& Oh, H. O. (2017). Effects of social support and psychological well-being on intention to exercise maintenance of elderly Pilates participants. Korean Journal of Physical Education, 56(1), 167-180.

Kim, S. K., Jeong, Y. D., \& Ha, J. H. (2018). The influence of motivation and psychological well-being on satisfaction and behavioral intention of golf participants. Korean Association for Leaner-centered Curriculum and Instruction, 18(22), 1247-1265.

Kim, Y. K., \& Kim, S. B. (2017). Relationship among participation motivation, exercise passion, and psychological well-being of crossfit participants. Journal of Coaching Development, 19(2), 30-38.

Kline, R. B. (2005). Principles and practice of structural equation modeling, 2nd ed. New York: Guilford publications.

Lee, K. J., Lee, C. W., \& Moon, D. S. (2020). The relationship among participation motivation, ego-resiliency and psychological well-being of college student participating in Taekwondo club. Korean Journal of Leisure, Recreation \& Park, 44(1), 15-27.

Lee, Y. S., \& Jung, H. K. (2019). Effect of Pilates on 
subjective and psychological well-being of college students majoring in Dance. The Korean Society of Dance Studies, 19(3), 63-73.

Lin, C. H. (2014). Effects of cuisine experience, psychological well-being, and self-health perception on the revisit intention of hot springs tourists. Journal of Hospitality \& Tourism Research, 38(2), 243-265.

Locker, D., Clarke, M. A., \& Payne, B. (2000). Self-perceived oral health status, psychological well-being, and life satisfaction in an older adult population. Journal of Dental Research, 79(4), 970-975

Mannell, R. C., \& Kleiber, D. A. (1997). A social psychology of leisure. State College, PA: Venture.

Maxham III, J. G. (2001). Service recovery's influence on consumer satisfaction, positive word-of-mouth, and purchase intentions. Journal of Business Research, 54(1), 11-24.

Maxham III, J. G., \& Netemeyer, R. G. (2002). Modeling customer perceptions of complaint handling over time: the effects of perceived justice on satisfaction and intent. Journal of Retailing, 78(4), 239-252.

Memmedova, K. (2015). Impact of Pilates on anxiety attention, motivation, cognitive function and achievement of students: structural modeling. Procedia-Social and Behavioral Sciences, 186, 544-548.

Nunnally, J. C., \& Bernstein, I. H. (1994). Psychometric Theory (McGraw-Hill Series in Psychology) (Vol. 3). New York: McGraw-Hill.

Oh, H. O. (2019). Relationship among the self-determination, psychological well-being, satisfaction, and behavioral intention of Pilates participants. Journal of Korean Association of Physical Education and Sport for Girls and Women, 33(4), 63-81.

Park, K. B., Lee, C. W., \& Moon, D. S. (2020). The relationship among participation motivation, leisure flow and exercise adherence of college student participating in Taekwondo club. Korean Journal of
Sports Science, 29(2), 83-97.

Pelletier, L. G., Tuson, K. M., Fortier, M. S., Vallerand, R. J., Briere, N. M., \& Blais, M. R. (1995). Toward a new measure of intrinsic motivation, extrinsic motivation, and amotivation in sports: The Sport Motivation Scale (SMS). Journal of Sport and Exercise Psychology, 17(1), 35-53.

Peng, Y., Kim, S. H., \& Lee, B. C. (2018). A study on the relationship between participation motivation and psychological well-being of sports for all programme participants - Targeting on Henan Province in China. Korean Journal of Sports Science, 27(5), 121-132.

Petracovschi, S. (2014). Motivation in practicing Yoga \& Pilates and satisfying the need for self-knowledge. Timisoara Physical Education and Rehabilitation Journal, 7(13), 117-122.

Pratminingsih, S. A., Rudatin, C. L., \& Rimenta, T. (2014). Roles of motivation and destination image in predicting tourist revisit intention: A case of Bandung-Indonesia. International Journal of Innovation, Management and Technology, 5(1), 19.

Prayag, G., Hosany, S., Muskat, B., \& Del Chiappa, G. (2017). Understanding the relationships between tourists' emotional experiences, perceived overall image, satisfaction, and intention to recommend. Journal of Travel Research, 56(1), 41-54.

Raza, M. A., Siddiquei, A. N., Awan, H. M., \& Bukhari, K. (2012). Relationship between service quality, perceived value, satisfaction and revisit intention in hotel industry. Interdisciplinary Journal of Contemporary Research in Business, 4(8), 788-805.

Roh, S. Y. (2016). The relationship between physical self-description, psychological well-being and subjective happiness of Pilates Participants. Korean Journal of Physical Education, 55(1), 207-219.

Ryan, R. M. (1995). Psychological needs and the facilitation of integrative processes. Journal of Personality, 63(3), 397-427.

Ryan, R. M., \& Deci, E. L. (2000). Intrinsic and extrinsic motivations: Classic definitions and new directions. 
Contemporary Educational Psychology, 25(1), 54-67.

Ryff, C. D. (1989). Happiness is everything, or is it? Explorations on the meaning of psychological well-being. Journal of Personality and Social Psychology, 57(6), 1069.

Ryff, C. D., \& Singer, B. H. (2008). Know thyself and become what you are: A eudaimonic approach to psychological well-being. Journal of Happiness Studies, 9(1), 13-39.

Scully, D., Kremer, J., Meade, M. M., Graham, R., \& Dudgeon, K. (1998). Physical exercise and psychological well being: a critical review. British Journal of Sports Medicine, 32(2), 111-120.

Sekendiz, B., Altun, Ö., Korkusuz, F., \& Akın, S. (2007). Effects of Pilates exercise on trunk strength, endurance and flexibility in sedentary adult females. Journal of Bodywork and Movement Therapies, 11(4), 318-326.

Seligman, M. (1975). Helplessness: On depression, development, and death. San Francisco, CA: Freeman.

Sirgy, M. J. (2010). Toward a quality-of-life theory of leisure travel satisfaction. Journal of Travel Research, 49(2), 246-260.

Sirgy, M. J., Gurel-Atay, E., Webb, D., Cicic, M., Husic-Mehmedovic, M., Ekici, A., ... \& Johar, J. S. (2013). Is materialism all that bad? Effects on satisfaction with material life, life satisfaction, and economic motivation. Social Indicators Research, 110(1), 349-366.

Suldo, S. M., \& Huebner, E. S. (2004). Does life satisfaction moderate the effects of stressful life events on psychopathological behavior during adolescence?. School Psychology Quarterly, 19(2), 93.

Um, S., Chon, K., \& Ro, Y. (2006). Antecedents of revisit intention. Annals of Tourism Research, 33(4), 1141-1158.

Weiss, M. R., \& Petlichkoff, L. M. (1989). Children’s motivation for participation in and withdrawal from sport: Identifying the missing links. Pediatric Exercise Science, 1(3), 195-211.

Whang, C. S., \& Kim, K. H. (2018). The effect of the motivation of participating in Nepal Himalaya trekking on leisure satisfaction and intention of return visit. The Korean Society of Sports Science. 27(2), 153-166.

White, R. W. (1959). Motivation reconsidered: The concept of competence. Psychological Review, 66(5), 297-333.

Wright, T. A., \& Cropanzano, R. (2000). Psychological well-being and job satisfaction as predictors of job performance. Journal of Occupational Health Psychology, 5(1), 84.

Yoon, S. M., \& Kim, T. H. (2019). The influence of psychological wellbeing on leisure attitude and leisure satisfaction in the participants in the college physical education. Korea Sport Society, 17(2), 27-37.

Yu, H. S., Hwang, I. S., \& Park, M. K. (2010). The causal relationship between women university students' motivation of participation, attitude and loyalty in intramural sports. Journal of Sport and Leisure Studies, 41, 231-241. 